\title{
The Optical and Microstructural Characterization of the Polymeric Thin Films with Self-Assembly Nanoparticles Prepared by Spin-Coating Techniques
}

\author{
Kwang-Ming Lee $\left.{ }^{1}{ }^{(}\right)$, Chia-Hong Huang ${ }^{2, *} \mathbb{C}$, Chia-Yu Chang ${ }^{1}$ and Chung-Cheng Chang ${ }^{3}$ \\ 1 Department of Chemistry, National Kaohsiung Normal University, Kaohsiung 82444, Taiwan; \\ kmlee@nknu.edu.tw (K.-M.L.); dig212000@hotmail.com (C.-Y.C.) \\ 2 Department of Electronic Engineering, National Kaohsiung Normal University, Kaohsiung 82444, Taiwan \\ 3 Department of Electrical Engineering, National Taiwan Ocean University, Keelung 20224, Taiwan; \\ ccchang@mail.ntou.edu.tw \\ * Correspondence: chhuang@nknu.edu.tw; Tel.: +886-7-7172930 (ext. 7913)
}

Received: 7 April 2020; Accepted: 9 May 2020; Published: 11 May 2020

\begin{abstract}
A-PEGCP) has been synthesized from maleic anhydride, poly(ethylene glycol) and bisphenol-A diglycidyl ether without using any organic solvent. The thin films produced from A-PEGCP solution were spin-coated on ITO-coated glass. The nanoparticles are observed in the thin films. It is proposed that the nanoparticle is built by a self-assembly process with bisphenol-A aggregates and poly (ethylene glycol) moieties. The effects of concentration, thermal annealing, excitation wavelength and moisture on the optical and nanostructured characterization of the thin films are investigated in this study. Photoluminescence (PL) spectrum of the thin film on ITO-coated glass has a peak of about $450 \mathrm{~nm}$ that extends from 360 to $550 \mathrm{~nm}$ under $325 \mathrm{~nm}$ excitation. The increase in PL intensity is accompanied by a red shift of PL spectrum as concentration increases. Moreover, the slightly red shift of PL spectrum is also observed as annealing temperature increases. Meanwhile, PL intensity negligibly decreases with annealing temperature. The degradation in PL intensity is apparent due to moisture. The excitation-wavelength dependent photoluminescence (EWDP) is observed in the thin film. UV-Vis absorption spectra of the thin films are red-shifted with concentration due to more molecular aggregation. The highest occupied molecular orbital (HOMO) energy is $-9.52 \mathrm{eV}$. The optical band-gap energy is $4.09-4.44 \mathrm{eV}$.
\end{abstract}

Keywords: photoluminescence; fluorescence; self-assembly nanoparticles; thin films

\section{Introduction}

In the past decade intensive attention has been paid to organic materials for their potential applications in flexible displays and solid-state lighting [1-8]. Specifically, for organic compounds with large molecular mass, wet-processing techniques are more suitable and developed in industry. Polymer light-emitting diodes (PLEDs) exhibit lower power consumption, faster response times, larger viewing angles, smaller sizes and greater ranges of color and contrast, along with being inexpensive and rapid to produce. Therefore, it provides simple manufacturing processes such as spin coating [9-12] or ink-jet printing [13-19] to produce large area displays or lighting. Nevertheless, PLEDs still suffer from lower performances in terms of their reliability and lifetime. Moreover, large molecular organic compounds are mainly $\pi$-conjugated materials. Generally, $\pi$-conjugated polymers are prepared by polycondensation based on catalytic cross-coupling reactions. However, the pre-preparation of organometallic reagents and by-production of a stoichiometric amount of toxic compounds are often involved in the cross-coupling reactions. These disadvantages have been a concern in industrial applications. Thus, new polymers are increasingly designed and synthesized [20-32]. In addition, 
conjugated polymers are organic macromolecules that are characterized by a backbone chain of alternating double- and single-bonds. Their overlapping p-orbitals produce a system of delocalized $\pi$-electrons, which give rise to their semiconductor properties. Nevertheless, the non-conjugated polymer does not have a backbone chain of alternating double- and single-bonds. Therefore, it is a wide band-gap material.

Over the past decade, the green synthesis has attracted considerable attention. For green chemistry, it is suggested that three main factors in nanoparticle preparation should be considered: solvent choice, the utilization of an environmentally benign reducing agent and the utilization of a non-toxic material. Hence, any synthetic procedure or chemical process should satisfy these principles by using environmentally benign solvents and nontoxic chemicals. Especially, newly developed reactions and polymers are expected to provide further advances in a sustainable society. In a synthesis, therefore, the best solvent is either no solvent, or water [33]. We have synthesized A-PEGCP with self-assembly nanoparticles without the use of organometallic reagents and solvent. A-PEGCP is a non-conjugated polymer. In our previous report, the effects of excitation wavelength and substrate on the photoluminescence of the polymeric thin film were investigated [34]. In this study, the thin films prepared from A-PEGCP solution were spin-coated on ITO-coated glass. In addition to excitation wavelength, it is also found that the processing technology parameters significantly affect the optical and nanostructured characterization of the thin films. Hence, the optical and microstructural characteristics of the thin films are investigated by photoluminescence (PL), transmission electron microscopy (TEM), UV-Vis absorption spectrum and ultraviolet photoelectron spectroscopy (UPS). Generally, the light emission of conjugated polymers often suffers from aggregation-caused quenching (ACQ) effect [35] due to the formation of non-radiative species, which significantly limits the field of their applications, especially in optoelectronics. However, the characterization results reveal that the emission of A-PEGCP is not quenched in thin film state. That is, polymeric thin films prepared from A-PEGCP do not suffer from ACQ effect in this study. Meanwhile, the results also show the important role of concentration in the size of the nanoparticle in the thin films. Moreover, the UV-Vis absorption spectra of the thin films are red-shifted with the concentration of the solution. The mean diameter of the nanoparticle is from 3.7 to $52.8 \mathrm{~nm}$ in the thin films prepared from 1 to $50 \mathrm{mM}$ solution, respectively. Furthermore, the peak of PL is gradually red-shifted with the increase in annealing temperature. In addition, the thin films exhibit the excitation-wavelength dependent photoluminescence (EWDP). The EWDP behavior has been rarely observed in thin solid films [34] and is ascribed to a size distribution of nanoparticles. The degradation of the thin film is due to the exposure to moisture. It is expected that A-PEGCP is used as a host material due to its excellent film-forming and wide band-gap properties in optoelectronic applications.

\section{Experimental}

All chemicals obtained from commercial sources were used as received. In a synthesis procedure, $1 \mathrm{mmol}$ of maleic anhydride was mixed with $0.5 \mathrm{mmol}$ of polyethylene glycol (PEG) 6000 under stirring in $\mathrm{N}_{2}$ ambient at $90^{\circ} \mathrm{C}$ for $1.5 \mathrm{~h}$ without using any solvent. The crude product was recrystallized twice from ether, then a white solid was obtained and was called product A. Subsequently, product A $(5.5 \mathrm{~g}, 4.6 \mathrm{mmol})$ and bisphenol A diglycidyl ether $(1.57 \mathrm{~g}, 4.6 \mathrm{mmol})$ were mixed and stirred at $120^{\circ} \mathrm{C}$ for $3 \mathrm{~h}$ in $\mathrm{N}_{2}$ ambient, then were cooled to room temperature. Finally, the synthesized polymer was obtained. It was called anhydride-poly(ethylene glycol) co-polymer (A-PEGCP). In this study, A-PEGCP was synthesized according to the reported synthesis procedures [34] and all processing was at pressures of one atmosphere.

The ITO-coated glass substrates $(12 \mathrm{~mm} \times 12 \mathrm{~mm})$ were cleaned with acetone and isopropanol in an ultrasonic bath and then treated with UV-ozone. A-PEGCP was dissolved in tetrahydrofuran (THF) with stirring for $24 \mathrm{~h}$. The polymeric thin films prepared by using various solutions $(1 \mathrm{mM}, 5 \mathrm{mM}$, $10 \mathrm{mM}, 25 \mathrm{mM}$ and $50 \mathrm{mM}$ ) were spin-coated for $40 \mathrm{~s}$ with $2000 \mathrm{rpm}$ on ITO-coated glass substrates, 
and then annealed at different temperatures $\left(80^{\circ} \mathrm{C}, 100{ }^{\circ} \mathrm{C}, 120^{\circ} \mathrm{C}\right.$ and $140{ }^{\circ} \mathrm{C}$, respectively) in $\mathrm{N}_{2}$ ambient for $1 \mathrm{~h}$.

Nanostructured properties of the thin films were examined by JEOL JEM-2100 TEM (Tokyo, Japan). PL spectra of the thin films were measured by a Hitachi F-4500 fluorescence spectrophotometer (Tokyo, Japan) and recorded in the range of 400-700 nm at $325 \mathrm{~nm}$ excitation wavelength at room temperature. UV-Vis absorption spectrum was measured by Shimadzu $3100 \mathrm{UV}$-Vis spectrophotometer (Tokyo, Japan) and employed to estimate the optical band-gap energy $\left(\mathrm{E}_{\mathrm{g}}\right)$. UPS was measured by ULVAC-PHI PHI 5000 Versaprobe II (Kanagawa, Japan). Meanwhile, it was operated with He for photon energies of $21.2 \mathrm{eV}$ and used to determine the binding energies of the highest occupied molecular orbital (HOMO) of the thin film. The thickness of the thin films was measured by surface profiler (Bruker Dektak XT) (Billerica, MA, USA). Meanwhile, the thickness of the thin films prepared from various solutions ( $1 \mathrm{mM}, 5 \mathrm{mM}, 10 \mathrm{mM}, 25 \mathrm{mM}$ and $50 \mathrm{mM}$ ) are $192 \mathrm{~nm}, 258 \mathrm{~nm}, 288 \mathrm{~nm}, 384 \mathrm{~nm}$, and $1105 \mathrm{~nm}$, respectively.

\section{Results and Discussion}

In general, organic solvents are volatile, flammable and toxic. However, they are often used in a synthesis. Furthermore, most organic waste created by the chemical synthesis is attributable to organic solvents. Thus, an important issue is the use of alternative reaction media to overcome the problems associated with many of the traditional volatile organic solvents. It is believed that the best solvent is no solvent, or water [33]. Figure 1 shows the chemical structure of A-PEGCP. In this study, A-PEGCP is synthesized without using hazardous substances and any organic solvent at ambient pressure in a synthesis. Therefore, the synthesized processing has satisfied these principles [36] in this study.

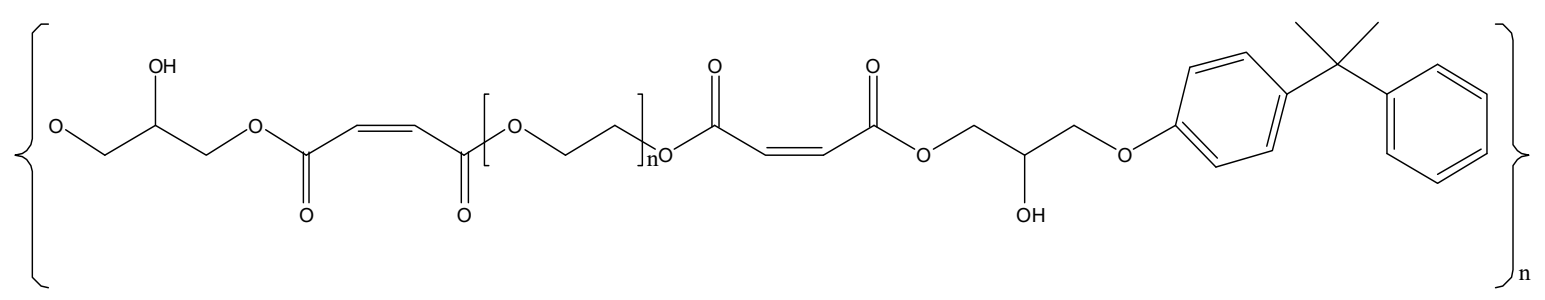

Figure 1. Chemical structure of anhydride-poly(ethylene glycol) co-polymer (A-PEGCP).

Figure 2 depicts PL spectra of the polymeric thin films prepared by using various solutions $\left(1 \mathrm{mM}, 5 \mathrm{mM}, 10 \mathrm{mM}, 25 \mathrm{mM}\right.$ and $50 \mathrm{mM}$, respectively) and annealed at $140{ }^{\circ} \mathrm{C}$. The PL peak of the polymeric thin film on ITO-coated glass is about $450 \mathrm{~nm}$ that extends from 360 to $650 \mathrm{~nm}$. It also indicates that PL intensity of the polymeric thin film is concentration-dependent and increases with solution concentration. Traditional organic fluorescent materials that are composed of $\pi$-conjugated frameworks generally exhibit high-efficiency luminescence in diluted solution. Nevertheless, severe luminescence quenching of the fluorescent materials usually occurs in highly concentrated solutions or in the solid state because non-radiative pathways are formed in the short-range molecular interactions, such as $\pi-\pi$ stacking originating from the planarity of the molecular skeleton. This phenomenon is known as aggregation-caused quenching (ACQ) [35]. In contrast, the result in Figure 2 suggests that the thin films prepared from A-PEGCP do not suffer from ACQ effect in this study. Generally, to maximize the performance of PLEDs, it is necessary for a polymeric thin film to avoid concentration quenching. From this point of view, the thin film prepared from A-PEGCP is appropriate for optoelectronic applications. 


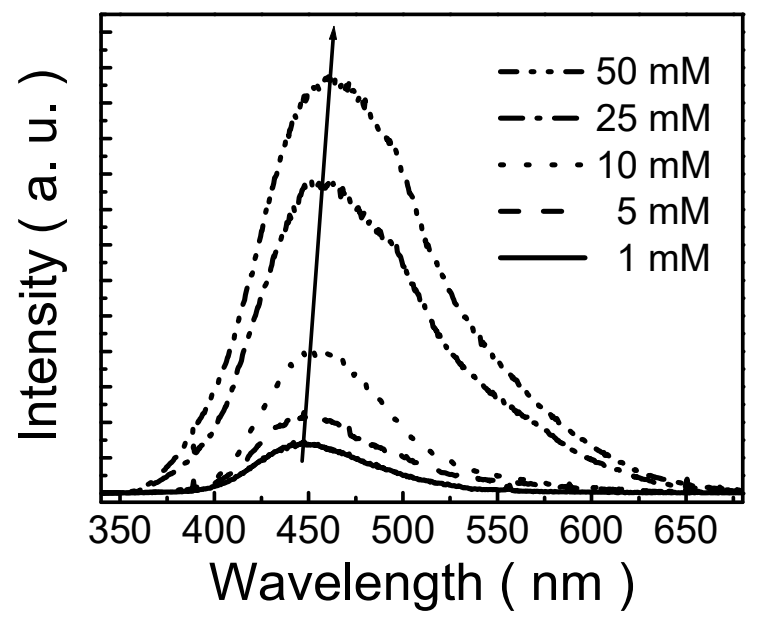

Figure 2. PL spectra of polymeric thin films prepared from various solutions $(1 \mathrm{mM}, 5 \mathrm{mM}, 10 \mathrm{mM}$, $25 \mathrm{mM}$ and $50 \mathrm{mM}$ ) and annealed at $140{ }^{\circ} \mathrm{C}$.

On the other hand, the emission peak is gradually red-shifted from 447 to $461 \mathrm{~nm}$ when the concentration is changed from 1 to $50 \mathrm{mM}$. In other words, the PL peak shifts toward the longer wavelengths (a red shift) with increasing the concentration. It is generally suggested that the PL peak exhibits a blue shift with decreasing the size of nanostructure due to quantum confinement [37]. Accordingly, it is proposed that the diameter of the self-assembly nanoparticle decreases with decreasing the concentration in this study. That is, the higher the concentration of the A-PEGCP solution, the larger the size of the self-assembly nanoparticle. This can be attributed to the large amount of the polymers (higher concentration) that leads to larger self-assembly nanoparticle formation. Thus, PL peak exhibits a red shift as the concentration increases.

Figure 3 indicates UV-Vis absorption spectra of the polymeric thin films prepared from 1 to $50 \mathrm{mM}$ solutions and annealed at $140{ }^{\circ} \mathrm{C}$. It is observed that the spectra of the thin films are red-shifted with the concentration of the solution, indicating more molecular aggregation and stronger intermolecular interactions [38] in the polymeric thin film prepared from the higher concentrated solutions. That is, the higher the concentration, the more molecular aggregation. On the other hand, the most common technique for the determination of the optical band-gap energy $\left(\mathrm{E}_{\mathrm{g}}\right)$ is optical absorption. An exciton is created by the absorption of a photon; the optical $\mathrm{E}_{\mathrm{g}}$ is, therefore, derived from the onset of the optical absorption. The absorption onset is estimated by linear extrapolation of the low energy edge of the UV-Vis absorption spectrum. Consequently, as the concentrations of solutions are $1 \mathrm{mM}, 5 \mathrm{mM}$, $10 \mathrm{mM}, 25 \mathrm{mM}$ and $50 \mathrm{mM}$, the onset wavelengths $\left(\lambda_{\text {onset }}\right)$ are $279 \mathrm{~nm}, 287 \mathrm{~nm}, 290 \mathrm{~nm}, 293 \mathrm{~nm}$ and $303 \mathrm{~nm}$, respectively. The optical $E_{g}$ is calculated using the formula $E_{g}=1240 / \lambda_{\text {onset }}[39,40]$, here $\lambda_{\text {onset }}$ is the onset wavelength. Thus, the optical $\mathrm{E}_{\mathrm{g}}$ of the polymeric thin film prepared from 1 to $50 \mathrm{mM}$ solution decreases from 4.44 to $4.09 \mathrm{eV}$. This result suggests that the optical $\mathrm{E}_{\mathrm{g}}$ of the thin film decreases with increasing concentration. Although optical $\mathrm{E}_{\mathrm{g}}$ is smaller than the true $\mathrm{E}_{\mathrm{g}}$ because it does not take into account the exciton binding energy, it is generally used to estimate the difference between the highest occupied molecular orbital (HOMO) and the lowest unoccupied molecular orbital (LUMO) energy [41-43]. Thus it indicates that A-PEGCP with the wide $\mathrm{E}_{\mathrm{g}}$ can be a promising candidate for a host material in PLED applications. 


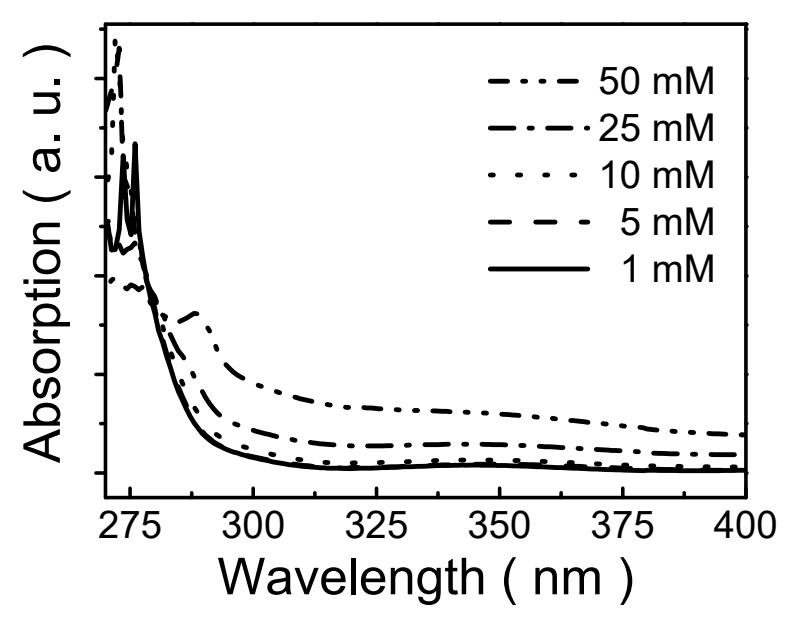

Figure 3. UV-Vis spectra of polymeric thin films prepared from various solutions $(1 \mathrm{mM}, 5 \mathrm{mM}, 10 \mathrm{mM}$, $25 \mathrm{mM}$ and $50 \mathrm{mM}$ ) and annealed at $140{ }^{\circ} \mathrm{C}$.

Figure 4 illustrates the mean diameter of the self-assembly nanoparticle in the polymeric thin film prepared by using various solutions ( $1 \mathrm{mM}, 5 \mathrm{mM}, 10 \mathrm{mM}, 25 \mathrm{mM}$ and $50 \mathrm{mM}$, respectively) and annealed at $140{ }^{\circ} \mathrm{C}$. The size of the nanoparticle in the thin film is extracted from TEM image (in Figure S1). With an increasing concentration (from 1 to $50 \mathrm{mM}$ ), the average size of the nanoparticle increases from $3.7 \pm 2.0 \mathrm{~nm}$ to $52.8 \pm 8.3 \mathrm{~nm}$. It has been proposed that the self-assembly nanoparticle is built of bisphenol-A aggregates and poly(ethylene glycol) moieties [34]. Therefore, the increase in the size of the nanoparticle with increasing concentration can be explained by the huge increase in the amount of bisphenol-A aggregates and poly(ethylene glycol) moieties in the higher concentrated solution. In other words, the larger amount (the higher concentration) of bisphenol-A aggregates and poly(ethylene glycol) moieties, the larger the diameter of the self-assembly nanoparticle. Accordingly, the results in Figure 4 are consistent with the results in Figures 2 and 3. Besides, the surface morphologies of the polymeric thin films prepared by using various solutions $(1 \mathrm{mM}, 5 \mathrm{mM}, 10 \mathrm{mM}, 25 \mathrm{mM}$ and $50 \mathrm{mM}$ ) are also shown in Figure S2.

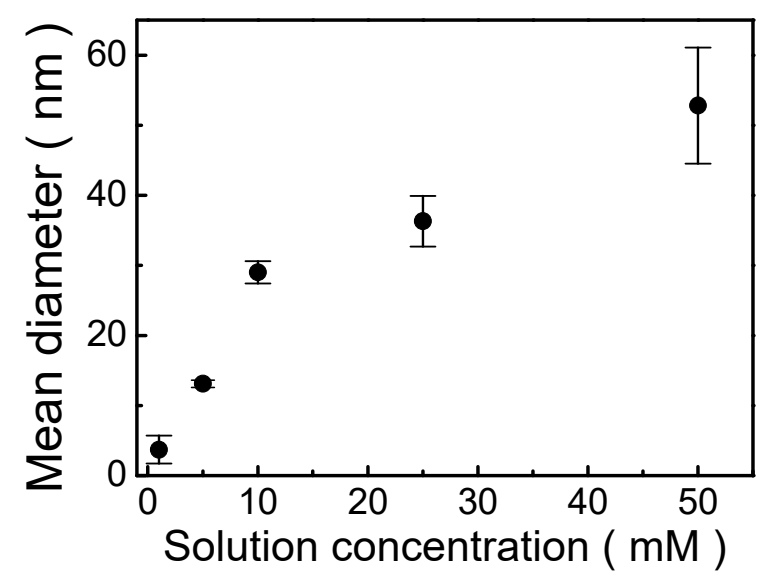

Figure 4. The mean diameter of the self-assembly nanoparticle as a function of solution concentration.

Figure 5 reveals PL spectra of polymeric thin films prepared from $1 \mathrm{mM}$ solution and annealed at different temperatures $\left(80^{\circ} \mathrm{C}, 100^{\circ} \mathrm{C}, 120^{\circ} \mathrm{C}\right.$ and $140{ }^{\circ} \mathrm{C}$, respectively). The PL intensity slightly decreases with annealing temperature. Moreover, the emission peak is slightly red-shifted from 436 to $441 \mathrm{~nm}$ as annealing temperature increases from 80 to $140{ }^{\circ} \mathrm{C}$. It is deduced that during annealing, solvent evaporation leads to partial dissociation of the self-assembly nanoparticles and subsequent 
reconstruction of the self-assembly nanoparticles [44]. So, the higher annealing temperature enhances nanoparticle reformation. Hence the nanoparticle size increases slightly with increasing annealing temperature so that PL spectra are red-shifted with annealing temperature. It is, therefore, worth noting that annealing is a critical process in the fabrication of nanoparticle-based films [45].

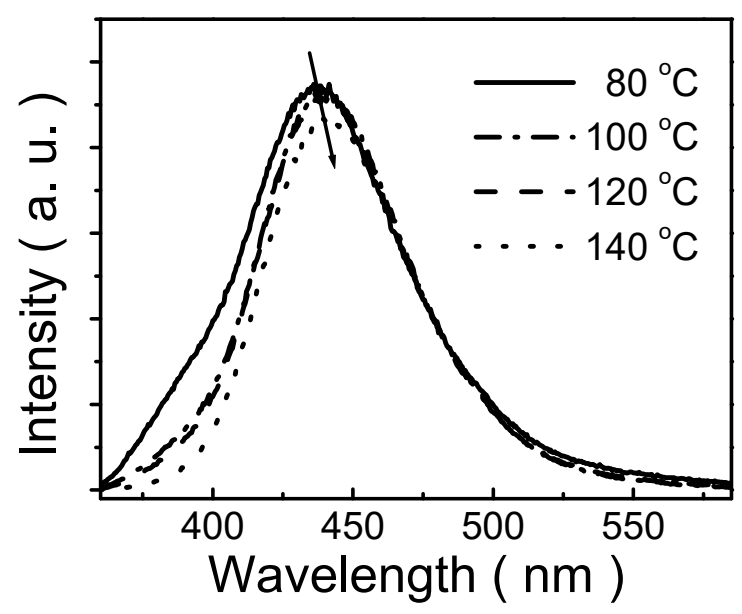

Figure 5. PL spectra of polymeric thin films prepared from a $1 \mathrm{mM}$ solution and annealed at various temperatures $\left(80^{\circ} \mathrm{C}, 100^{\circ} \mathrm{C}, 120^{\circ} \mathrm{C}\right.$ and $\left.140{ }^{\circ} \mathrm{C}\right)$.

Figure 6 displays PL spectra of the polymeric thin film prepared from $5 \mathrm{mM}$ solution under 266 and $325 \mathrm{~nm}$ excitations. The PL peak of the thin film on ITO-coated glass is about $446 \mathrm{~nm}$ that extends from 360 to $600 \mathrm{~nm}$ under excitation at $266 \mathrm{~nm}$. The thin film exhibits the EWDP behavior. The emission peak is red-shifted ( $5 \mathrm{~nm}$ ) with increasing excitation wavelength (from 266 to $325 \mathrm{~nm}$ ). Meanwhile, the EWDP phenomenon of A-PEGCP is not only observed in dichloromethane $\left(\mathrm{CH}_{2} \mathrm{Cl}_{2}\right)$, but also in water. Therefore, EWDP behavior of A-PEGCP is found in both solid thin film and liquid states. So far, the EWDP property has been rarely observed in thin films. The EWDP phenomenon is generally observed in solutions and ascribed to a size distribution in nanostructures, solvation process in polar solvent, photo-enhanced oxygen adsorption, photo-corrosion process and the advancing of fast ionization processes under higher energy excitation [46]. In this study, while the concentrations of the solutions are $1 \mathrm{mM}, 5 \mathrm{mM}, 10 \mathrm{mM}, 25 \mathrm{mM}$ and $50 \mathrm{mM}$, the size distributions of the nanoparticles in thin films are in the ranges of $0.7-5.9 \mathrm{~nm}, 5.8-14.1 \mathrm{~nm}, 17.7-45.2 \mathrm{~nm}, 14.5-80 \mathrm{~nm}$, and $15.3-61.2 \mathrm{~nm}$, respectively. Thus, it is suggested that the EWDP phenomenon is attributed to a size distribution of self-assembly nanoparticles, where the PL emission is dependent on the size of the self-assembly nanoparticle due to the quantum size effect in this study. 


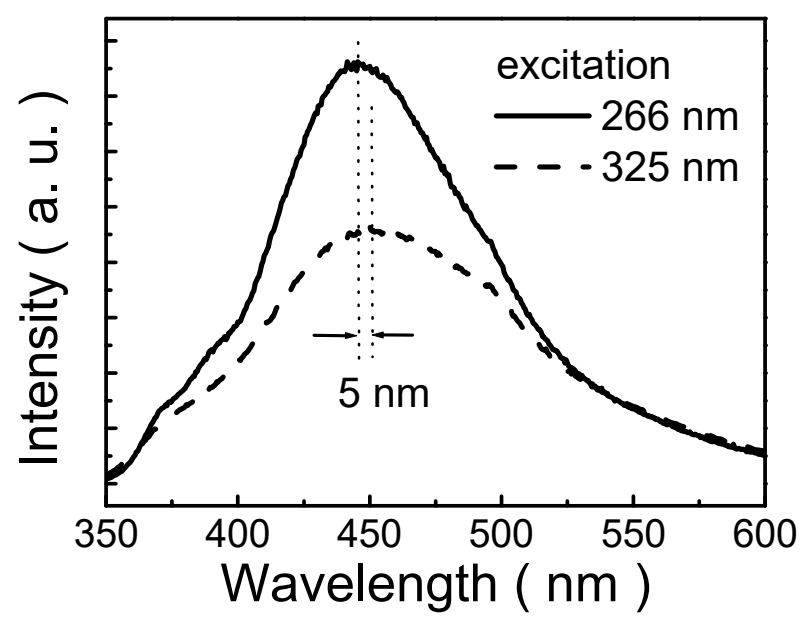

Figure 6. PL spectra of the polymeric thin film under 266 and $325 \mathrm{~nm}$ excitations.

Figure 7 demonstrates PL spectra of the polymeric thin film prepared from $1 \mathrm{mM}$ solution and annealed at $140{ }^{\circ} \mathrm{C}$ as deposited and prepared after seven months. It clearly shows that the PL intensity decreases with time. It is proposed that oxygen diffuses into the polymer from air and quenches the PL of the polymer to an extent that depends on the amount of oxygen present in the polymeric film [47,48]. Furthermore, the result also shows that the position of the PL emission peak is red-shifted with time. This red shift amounts to $14 \mathrm{~nm}$. It is deduced that localized shallow traps are formed in the band-tail states in the surface of the thin film due to the exposure to moisture without encapsulation [49]. These shallow trap states, energy levels close to HOMO and LUMO energy levels, can act as radiative recombination channels and emit photons with less energy than those related with the LUMO-to-HOMO transition, leading to a red shift in PL spectra.

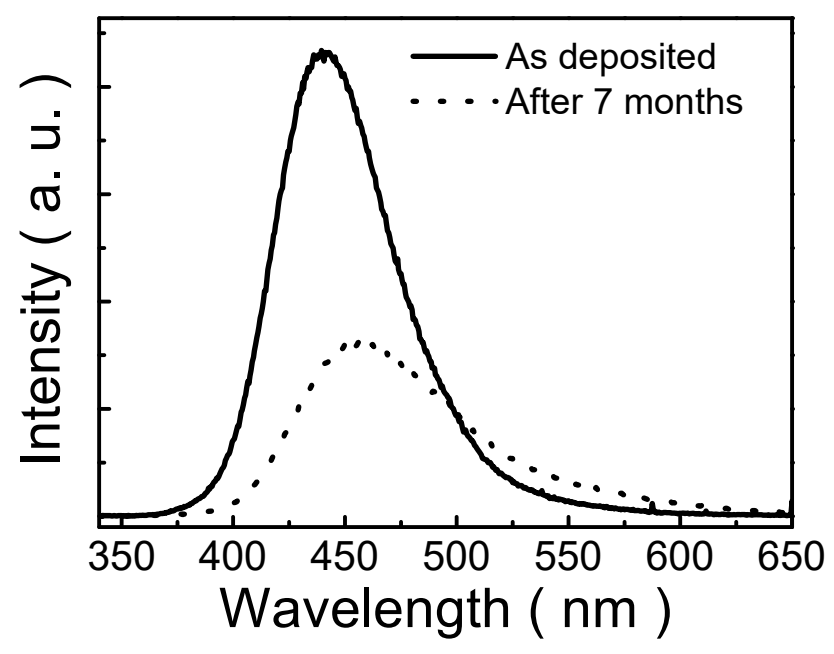

Figure 7. PL spectra of polymeric thin films as deposited and prepared after seven months.

Figure 8 presents the UPS spectrum of the polymeric thin film prepared from $10 \mathrm{mM}$ solution and annealed at $140{ }^{\circ} \mathrm{C}$ on Au-coated Si substrate. UPS is based on the photoelectric effect. UPS probes the energy of the occupied levels by using ultraviolet radiation. The ionization energy is determined by linearly extrapolating the high and low energy slopes of the spectrum to the spectral base lines. The HOMO position relative to the vacuum level is estimated by linearly extrapolating the low and high binding energy side of the spectrum to the base lines. That is, the intersection of the lines at high binding energy provides an estimate of the lowest energy electrons. The difference between the two energies is the maximum of the kinetic energy, $\mathrm{E}_{\mathrm{kin}}$, of the emitted HOMO electrons at the surface of 
the thin film, so HOMO energy is calculated from HOMO energy $=\mathrm{E}_{\mathrm{kin}}-21.2 \mathrm{eV}[50,51]$. Thus HOMO energy of the thin film prepared from A-PEGCP is estimated about $-9.52 \mathrm{eV}$.

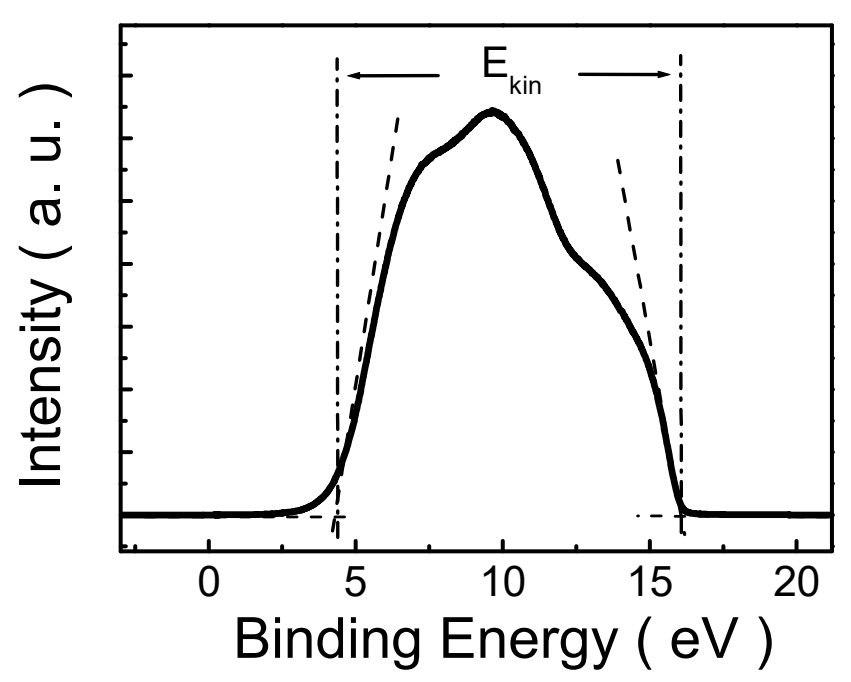

Figure 8. UPS spectrum of the polymeric thin film prepared from a $10 \mathrm{mM}$ solution and annealed at $140{ }^{\circ} \mathrm{C}$.

\section{Conclusions}

Thin films prepared from A-PEGCP with self-assembly nanoparticles that have been spin-coated on ITO-coated glass substrates are smooth and uniform. The TEM images demonstrate nanoparticles are formed with a mean diameter distribution ranging from 3.7 to $52.8 \mathrm{~nm}$ as the concentration increases from 1 to $50 \mathrm{mM}$. It is suggested that the increase in the size of the nanoparticle with increasing concentration can be ascribed to the enormous increase in the amount of bisphenol-A aggregates and poly(ethylene glycol) moieties in the higher concentrated solution. In addition, PL intensity increases with concentration. Thus, it clearly shows that there is no ACQ effect in the thin films. Meanwhile, PL spectra present a slight red shift $(14 \mathrm{~nm})$ with increasing concentrations from 1 to $50 \mathrm{mM}$. The UV-Vis absorption spectra of the thin films are also red-shifted with concentration, indicating more molecular aggregation and stronger intermolecular interactions in the thin films prepared from higher concentrated solutions. Furthermore, PL intensity slightly decreases with annealing temperature. Meanwhile, PL spectra also show a slight red shift $(5 \mathrm{~nm})$ with increasing annealing temperature from 80 to $140{ }^{\circ} \mathrm{C}$. It is proposed that the higher annealing temperature enhances the reconstruction of the self-assembly nanoparticles. The polymeric thin film exhibits the EWDP property with PL peaks ranging from 446 to $451 \mathrm{~nm}$ under excitation from 266 to $325 \mathrm{~nm}$. It is, therefore, suggested that EWDP behavior is ascribed to a nearly continuous size distribution of nanoparticles. Moreover, it is proposed that oxygen diffuses into the thin film from air and quenches the PL of the thin film. Meanwhile, the red shift of PL spectra with aging is attributed to localized shallow traps induced by moisture without encapsulation. Consequently, optical properties of polymeric thin films with self-assembly nanoparticles are influenced by concentration, thermal annealing, nanoparticle size and moisture. Besides, HOMO energy is obtained of about $-9.52 \mathrm{eV}$. The optical band gap is $4.09-4.44 \mathrm{eV}$. These results illustrate that the thin film with self-assembly nanoparticles is a promising candidate for a host material in PLED applications.

Supplementary Materials: The following are available online at http://www.mdpi.com/2073-4352/10/5/390/s1, Figure S1: TEM images of the self-assembly nanoparticles prepared from different concentration solutions (from 1 to $50 \mathrm{mM}$ ); Figure S2: the surface morphologies of the polymeric thin films prepared from different concentration solutions (from 1 to $50 \mathrm{mM}$ ).

Author Contributions: Conceptualization, K.-M.L. and C.-H.H.; methodology, K.-M.L. and C.-H.H.; validation, C.-H.H.; formal analysis, C.-H.H. and C.-C.C.; investigation, C.-Y.C. and C.-H.H.; writing-original draft 
preparation, C.-H.H.; writing-review and editing, C.-H.H.; supervision, C.-C.C.; project administration, C.-C.C. and C.-H.H. All authors have read and agreed to the published version of the manuscript.

Funding: This research received no external funding.

Acknowledgments: The authors thank Yi-Lin Yang for helpful discussions in PL analysis.

Conflicts of Interest: The authors declare no conflict of interest.

\section{References}

1. Höfle, S.; Pfaff, M.; Do, H.; Bernhard, C.; Gerthsen, D.; Lemmer, U.; Colsmann, A. Suppressing Molecular Aggregation in Solution Processed Small Molecule Organic Light Emitting Diodes. Org. Electron. 2014, 15, 337-341. [CrossRef]

2. Höfle, S.; Bruns, M.; Strässle, S.; Feldmann, C.; Lemmer, U.; Colsmann, A. Tungsten Oxide Buffer Layers Fabricated in an Inert Sol-Gel Process at Room-Temperature for Blue Organic Light-Emitting Diodes. Adv. Mater. 2013, 25, 4113-4116. [CrossRef] [PubMed]

3. Chiba, T.; Pu, Y.J.; Miyazaki, R.; Nakayama, K.; Sasabe, H.; Kido, J. Ultra-High Efficiency by Multiple Emission from Stacked Organic Light-Emitting Devices. Org. Electron. 2011, 12, 710-715. [CrossRef]

4. Kumar, A.; Srivastava, R.; Tyagi, P.; Mehta, D.S.; Kamalasanan, M.N. Effect of Doping of 8-Dydroxyquinolinatolithium on Electron Transport in Tris (8-hydroxyquinolinato) aluminum. J. Appl. Phys. 2011, 109, 114511. [CrossRef]

5. Liang, J.; Zhong, Z.; Li, S.; Jiang, X.-F.; Ying, L.; Yang, W.; Peng, J.; Cao, Y. Efficient White Polymer Light-Emitting Diodes from Single Polymer Exciplex Electroluminescence. J. Mater. Chem. C 2017, 5, 2397-2403. [CrossRef]

6. Ying, L.; Ho, C.-L.; Wu, H.; Cao, Y.; Wong, W.-Y. White Polymer Light-Emitting Devices for Solid-State Lighting: Materials, Devices, and Recent Progress. Adv. Mater. 2014, 26, 2459-2473. [CrossRef]

7. Zheng, H.; Zheng, Y.; Liu, N.; Ai, N.; Wang, Q.; Wu, S.; Zhou, J.; Hu, D.; Yu, S.; Han, S.; et al. All-Solution Processed Polymer Light-Emitting Diode Displays. Nat. Commun. 2013, 4, 1971. [CrossRef]

8. Yin, Y.; Ali, M.U.; Xie, W.; Yang, H.; Meng, H. Evolution of White Organic Light-Emitting Devices: From Academic Research to Lighting and Display Applications. Mater. Chem. Front. 2019, 3, 970-1031. [CrossRef]

9. Stanculescu, F.; Stanculescu, A.; Girtan, M.; Socol, M.; Rasoga, O. Effect of the Morphology on the Optical and Electrical Properties of Polycarbonate Film Doped with Aniline Derivatives Monomers. Synth. Met. 2012, 161, 2589-2597. [CrossRef]

10. Spadavecchia, J.; Ciccarella, G.; Siciliano, P.; Capone, S.; Rella, R. Spin-Coated Thin Films of Metal Porphyrin-Phthalocyanine Blend for an Optochemical Sensor of Alcohol Vapours. Sens. Actuators B Chem. 2004, 100, 88-93. [CrossRef]

11. Cosseddu, P.; Bonfiglio, A. Soft Lithography Fabrication of All-Organic Bottom-Contact and Top-Contact Field Effect Transistors. Appl. Phys. Lett. 2006, 88, 023506. [CrossRef]

12. Kasparek, C.; Blom, P.W.M. Solution-Processed Multilayer Polymer Light-Emitting Diode without Intermixing. Appl. Phys. Lett. 2017, 110, 023302. [CrossRef]

13. Aernouts, T.; Aleksandrov, T.; Girotto, C.; Genoe, J.; Poortmans, J. Polymer Based Organic Solar Cells Using Ink-Jet Printed Active Layers. Appl. Phys. Lett. 2008, 92, 033306. [CrossRef]

14. Hoth, C.N.; Choulis, S.A.; Schilinsky, P.; Brabec, C.J. On the Effect of Poly (3-hexylthiophene) Regioregularity on Inkjet Printed Organic Solar Cells. J. Mater. Chem. 2009, 19, 5398-5404. [CrossRef]

15. Eslamian, M. Inorganic and Organic Solution-Processed Thin Film Devices. Nano-Micro Lett. $2017,9,3$. [CrossRef]

16. Amruth, C.; Szymański, M.Z.; Łuszczyńska, B.; Ulański, J. Inkjet Printing of Super Yellow: Ink Formulation, Film Optimization, OLEDs Fabrication, and Transient Electroluminescence. Sci. Rep. 2019, 9, 8493. [CrossRef]

17. Zhan, Z.; An, J.; Wei, Y.; Van Tran, T.; Du, H. Inkjet-Printed Optoelectronics. Nanoscale 2017, 9, $965-993$. [CrossRef]

18. Kraft, T.M.; Berger, P.R.; Lupo, D. Printed and Organic Diodes: Devices, Circuits and Applications. Flex. Print. Electron. 2017, 2, 033001. [CrossRef]

19. Soleimani-Gorgani, A. Co-Solvents Roles in PEDOT:PSS Ink-Jet Inks. Adv. Nat. Sci. Nanosci. Nanotechnol. 2018, 9, 025009. [CrossRef] 
20. Lai, W.-Y.; Levell, J.W.; Balfour, M.N.; Burn, P.L.; Lo, S.-C.; Samuel, I.D.W. The 'Double Dendron' Approach to Host Free Phosphorescent Poly(dendrimer) OLEDs. Polym. Chem. 2012, 3, 734-740. [CrossRef]

21. Park, J.H.; Koh, T.-W.; Chung, J.; Park, S.H.; Eo, M.; Do, Y.; Yoo, S.; Lee, M.H. Polynorbornene Copolymer with Side-Chain Iridium(III) Emitters and Carbazole Hosts: A Single Emissive Layer Material for Highly Efficient Electrophosphorescent Devices. Macromolecules 2013, 46, 674-682. [CrossRef]

22. He, X.; Cai, D.; Kang, D.-Y.; Haske, W.; Zhang, Y.; Zuniga, C.A.; Wunsch, B.H.; Barlow, S.; Leisen, J.; Bucknall, D.; et al. Phosphorescent Light-Emitting Diodes Using Triscarbazole/bis (oxadiazole) Hosts: Comparison of Homopolymer Blends and Random and Block Copolymers. J. Mater. Chem. C 2014, 2, 6743-6751. [CrossRef]

23. Nobuyasu, R.S.; Ren, Z.; Griffiths, G.C.; Batsanov, A.S.; Data, P.; Yan, S.; Monkman, A.P.; Bryce, M.R.; Dias, F.B. Rational Design of TADF Polymers Using a Donor-Acceptor Monomer with Enhanced TADF Efficiency Induced by the Energy Alignment of Charge Transfer and Local Triplet Excited States. Adv. Opt. Mater. 2016, 4, 597-607. [CrossRef]

24. Sun, D.; Zhou, X.; Liu, J.; Sun, X.; Li, H.; Ren, Z.; Ma, D.; Bryce, M.R.; Yan, S. Solution-Processed Blue/Deep Blue and White Phosphorescent Organic Light-Emitting Diodes (PhOLEDs) Hosted by a Polysiloxane Derivative with Pendant mCP (1,3-bis (9-carbazolyl) benzene). ACS Appl. Mater. Interfaces 2015, 7, 27989-27998. [CrossRef] [PubMed]

25. Lee, K.-M.; Cheng, W.-Y.; Chen, C.-Y.; Shyue, J.-J.; Nieh, C.-C.; Chou, C.-F.; Lee, J.-R.; Lee, Y.-Y.; Cheng, C.-Y.; Chang, S.Y.; et al. Excitation-Dependent Visible Fluorescence in Decameric Nanoparticles with Monoacylglycerol Cluster Chromophores. Nat. Commun. 2013, 4, 1544. [CrossRef]

26. Botta, A.; Pragliola, S.; Venditto, V.; Rubino, A.; Aprano, S.; Mauro, A.D.G.D.; Maglione, M.G.; Minarini, C. Synthesis, Characterization, and Use as Emissive Layer of White Organic Light Emitting Diodes of the Highly Isotactic Poly (N-pentenyl-carbazole). Polym. Compos. 2015, 36, 1110-1117. [CrossRef]

27. Nikolaenko, A.E.; Cass, M.; Bourcet, F.; Mohamad, D.; Roberts, M. Thermally Activated Delayed Fluorescence in Polymers: A New Route toward Highly Efficient Solution Processable OLEDs. Adv. Mater. 2015, 27, 7236-7240. [CrossRef]

28. Cappelli, A.; Razzano, V.; Fabio, G.; Paolino, M.; Grisci, G.; Giuliani, G.; Donati, A.; Mendichi, R.; Mróz, W.; Villafiorita-Monteleone, F; et al. Side Chain Engineering in $\pi$-Stacked Polybenzofulvene Derivatives Bearing Electron-Rich Chromophores for OLED Applications. RSC Adv. 2015, 5, 101377-101385. [CrossRef]

29. Ren, Z.; Nobuyasu, R.S.; Dias, F.B.; Monkman, A.P.; Yan, S.; Bryce, M.R. Pendant Homopolymer and Copolymers as Solution-Processable Thermally Activated Delayed Fluorescence Materials for Organic Light-Emitting Diodes. Macromolecules 2016, 49, 5452-5460. [CrossRef]

30. Page, Z.A.; Chiu, C.-Y.; Narupai, B.; Laitar, D.S.; Mukhopadhyay, S.; Sokolov, A.; Hudson, Z.M.; Zerdan, R.B.; McGrath, A.J.; Kramer, J.W.; et al. Highly Photoluminescent Nonconjugated Polymers for Single-Layer Light Emitting Diodes. ACS Photonics 2017, 4, 631-641. [CrossRef]

31. Shao, S.; Wang, S.; Xu, X.; Yang, Y.; Lv, J.; Ding, J.; Wang, L.; Jing, X.; Wang, F. Realization of High-Power-Efficiency White Electroluminescence from a Single Polymer by Energy-Level Engineering. Chem. Sci. 2018, 9, 8656-8664. [CrossRef] [PubMed]

32. Wang, J.; Wang, N.; Wu, G.; Wang, S.; Li, X. Multicolor Emission from Non-conjugated Polymers Based on a Single Switchable Boron Chromophore. Angew. Chem. Int. Ed. 2019, 58, 3082-3086. [CrossRef] [PubMed]

33. Sheldon, R.A. Green Solvents for Sustainable Organic Synthesis: State of the Art. Green Chem. 2005, 7, 267-278. [CrossRef]

34. Huang, C.-H.; Chang, C.-C.; Lee, K.-M.; Wang, J.-M.; Liu, C.-Y. Excitation-Wavelength-Dependent and Substrate-Dependent Photoluminescence from the Non-Conjugated Polymeric Thin Film with Self-Assembly Nanoparticles. IEEE Photonics J. 2018, 10, 2600108. [CrossRef]

35. Jenekhe, S.A.; Osaheni, J.A. Excimers and Exciplexes of Conjugated Polymers. Science 1994, 265, 765-768. [CrossRef]

36. Anastas, P.; Eghbali, N. Green Chemistry: Principles and Practice. Chem. Soc. Rev. 2010, 39, 301-312. [CrossRef]

37. Ekimov, A.I.; Efros, A.L.; Onushchenko, A.A. Quantum Size Effect in Semiconductor Microcrystals. Solid State Commun. 1993, 88, 947-950. [CrossRef] 
38. Zhang, C.; Zhang, J.; Zeng, W.; Zheng, N.; Li, W.; Gao, W.; Yu, G.; Yang, C. Benzobisthiadiazole-alt-bithiazole copolymers with deep HOMO levels for good-performance field-effect transistors with air stability and a high on/off ratio. Polym. Chem. 2016, 7, 2808-2814. [CrossRef]

39. Costa, J.C.S.; Taveira, R.J.S.; Lima, C.F.R.A.C.; Mendes, A.; Santos, L.M.N.B.F. Optical Band Gaps of Organic Semiconductor Materials. Opt. Mater. 2016, 58, 51-60. [CrossRef]

40. Bhadwal, A.S.; Tripathi, R.M.; Gupta, R.K.; Kumar, N.; Singh, R.P.; Shrivastav, A. Biogenic synthesis and photocatalytic activity of CdS nanoparticles. RSC Adv. 2014, 4, 9484-9490. [CrossRef]

41. Ishii, H.; Sugiyama, K.; Ito, E.; Seki, K. Energy Level Alignment and Interfacial Electronic Structures at Organic/Metal and Organic/Organic Interfaces. Adv. Mater. 1999, 11, 605-625. [CrossRef]

42. Tengstedt, C.; Osikowicz, W.; Salaneck, W.R.; Parker, I.D.; Hsu, C.-H.; Fahlman, M. Fermi-Level Pinning at Conjugated Polymer Interfaces. Appl. Phys. Lett. 2006, 88, 053502. [CrossRef]

43. Seo, J.H.; Pedersen, T.M.; Chang, G.S.; Moewes, A.; Yoo, K.-H.; Cho, S.J.; Whang, C.N. Probing Interfacial Characteristics of Rubrene/Pentacene and Pentacene/Rubrene Bilayers with Soft X-Ray Spectroscopy. J. Phys. Chem. B 2007, 111, 9513-9518. [CrossRef]

44. Lee, M.; Cho, Y.W.; Park, J.H.; Chung, H.; Jeong, S.Y.; Choi, K.; Moon, D.H.; Kim, S.Y.; Kim, I.-S.; Kwon, I.C. Size Control of Self-Assembled Nanoparticles by an Emulsion/Solvent Evaporation Method. Colloid Polym. Sci. 2006, 284, 506-512. [CrossRef]

45. Bensebaa, F.; Durand, C.; Aouadou, A.; Scoles, L.; Du, X.; Wang, D.; Le Page, Y. A New Green Synthesis Method of $\mathrm{CuInS}_{2}$ and CuInSe 2 Nanoparticles and Their Integration into Thin Films. J. Nanopart. Res. 2010, 12, 1897-1903. [CrossRef]

46. Osman, M.A.; Abd-Elrahim, A.G. Excitation Wavelength Dependent Photoluminescence Emission Behavior, UV Induced Photoluminescence Enhancement and Optical Gap Tuning of Zn0.45Cd0.55S Nanoparticles for Optoelectronic Applications. Opt. Mater. 2018, 77, 1-12. [CrossRef]

47. Amao, Y.; Asai, K.; Okura, I. Photoluminescent Oxygen Sensing Using Palladium Tetrakis (4-carboxyphenyl) porphyrin Self-Assembled Membrane on Alumina. Anal. Commun. 1999, 36, 179-180. [CrossRef]

48. Lu, X.; Winnik, M.A. Luminescence Quenching in Polymer/Filler Nanocomposite Films Used in Oxygen Sensors. Chem. Mater. 2001, 13, 3449-3463. [CrossRef]

49. Niu, L.; Liu, X.F.; Cong, C.X.; Wu, C.Y.; Wu, D.; Chang, T.R.; Wang, H.; Zeng, Q.S.; Zhou, J.D.; Wang, X.L.; et al. Controlled Synthesis of Organic/Inorganic van der Waals Solid for Tunable Light-Matter Interactions. Adv. Mater. 2015, 27, 7800-7808. [CrossRef]

50. D'Andrade, B.W.; Datta, S.; Forrest, S.R.; Djurovich, P.; Polikarpov, E.; Thompson, M.E. Relationship between the Ionization and Oxidation Potentials of Molecular Organic Semiconductors. Org. Electron. 2005, 6, 11-20. [CrossRef]

51. Liao, L.S.; Fung, M.K.; Lee, C.S.; Lee, S.T.; Inbasekaran, M.; Woo, E.P.; Wu, W.W. Electronic Structure and Energy Band Gap of Poly (9,9-dioctylfluorene) Investigated by Photoelectron Spectroscopy. Appl. Phys. Lett. 2000, 76, 3582. [CrossRef]

(C) 2020 by the authors. Licensee MDPI, Basel, Switzerland. This article is an open access article distributed under the terms and conditions of the Creative Commons Attribution (CC BY) license (http://creativecommons.org/licenses/by/4.0/). 